Swarthmore College

Works

$11-22-2005$

\title{
Second OH Overtone Excitation And Statistical Dissociation Dynamics Of Peroxynitrous Acid
}

\author{
I. M. Konen \\ E. X.J. Li \\ Thomas Alex Stephenson \\ Swarthmore College, tstephe1@swarthmore.edu
}

M. I. Lester

Follow this and additional works at: https://works.swarthmore.edu/fac-chemistry

Part of the Physical Chemistry Commons

Let us know how access to these works benefits you

\section{Recommended Citation}

I. M. Konen, E. X.J. Li, Thomas Alex Stephenson, and M. I. Lester. (2005). "Second OH Overtone Excitation And Statistical Dissociation Dynamics Of Peroxynitrous Acid". Journal Of Chemical Physics. Volume 123, Issue 20. DOI: 10.1063/1.2126968

https://works.swarthmore.edu/fac-chemistry/15

This work is brought to you for free by Swarthmore College Libraries' Works. It has been accepted for inclusion in Chemistry \& Biochemistry Faculty Works by an authorized administrator of Works. For more information, please contact myworks@swarthmore.edu. 


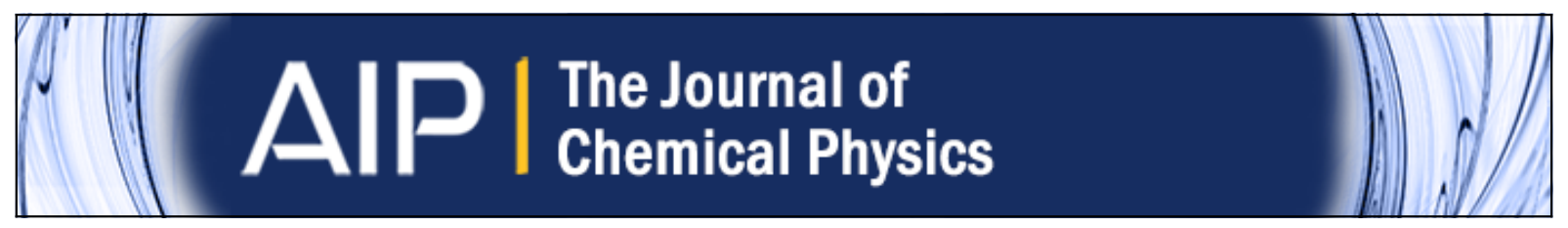

Second $\mathrm{OH}$ overtone excitation and statistical dissociation dynamics of peroxynitrous acid

Ian M. Konen, Eunice X. J. Li, Thomas A. Stephenson, and Marsha I. Lester

Citation: The Journal of Chemical Physics 123, 204318 (2005); doi: 10.1063/1.2126968

View online: http://dx.doi.org/10.1063/1.2126968

View Table of Contents: http://scitation.aip.org/content/aip/journal/jcp/123/20?ver=pdfcov

Published by the AIP Publishing

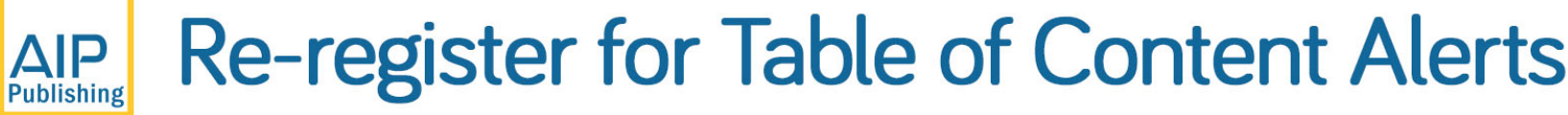




\title{
Second $\mathrm{OH}$ overtone excitation and statistical dissociation dynamics of peroxynitrous acid
}

\author{
Ian M. Konen, Eunice X. J. Li, Thomas A. Stephenson, a) and Marsha I. Lester ${ }^{\text {b) }}$ \\ Department of Chemistry, University of Pennsylvania, Philadelphia, Pennsylvania 19104-6323
}

(Received 11 August 2005; accepted 28 September 2005; published online 29 November 2005)

\begin{abstract}
The second $\mathrm{OH}$ overtone transition of the trans-perp conformer of peroxynitrous acid (tp-HOONO) is identified using infrared action spectroscopy. HOONO is produced by the recombination of photolytically generated $\mathrm{OH}$ and $\mathrm{NO}_{2}$ radicals, and then cooled in a pulsed supersonic expansion. The second overtone transition is assigned to tp-HOONO based on its vibrational frequency $\left(10195.3 \mathrm{~cm}^{-1}\right)$ and rotational band contour, which are in accord with theoretical predictions and previous observations of the first overtone transition. The transition dipole moment associated with the overtone transition is rotated considerably from the $\mathrm{OH}$ bond axis, as evident from its hybrid band composition, indicating substantial charge redistribution upon $\mathrm{OH}$ stretch excitation. The overtone band exhibits homogeneous line broadening that is attributed to intramolecular vibrational redistribution, arising from the coupling of the initially excited $\mathrm{OH}$ stretch to other modes that ultimately lead to dissociation. The quantum state distributions of the $\mathrm{OH} X^{2} \Pi(\nu=0)$ products following first and second $\mathrm{OH}$ overtone excitation of tp-HOONO are found to be statistical by comparison with three commonly used statistical models. The product state distributions are principally determined by the tp-HOONO binding energy of $16.2(1) \mathrm{kcal} \mathrm{mol}^{-1}$. Only a small fraction of the $\mathrm{OH}$ products are produced in $\nu=1$ following the second overtone excitation, consistent with statistical predictions. (C) 2005 American Institute of Physics.
\end{abstract}

[DOI: $10.1063 / 1.2126968]$

\section{INTRODUCTION}

The three-body association reaction of $\mathrm{OH}$ with $\mathrm{NO}_{2}$ to produce stable nitric acid $\left(\mathrm{HONO}_{2}\right)$,

$$
\mathrm{OH}+\mathrm{NO}_{2}+\mathrm{M} \rightarrow \mathrm{HONO}_{2}+\mathrm{M},
$$

is a key termination step of the radical chemistry that occurs in the lower atmosphere. ${ }^{1}$ This process terminates many reactions involving $\mathrm{HO}_{x}\left(\mathrm{HO}_{x} \equiv \mathrm{OH}+\mathrm{HO}_{2}\right)$ and $\mathrm{NO}_{x}\left(\mathrm{NO}_{x}\right.$ $\left.\equiv \mathrm{NO}+\mathrm{NO}_{2}\right)$ species that would otherwise lead to photochemical smog. Until recently, this intramolecular reaction was believed to produce $\mathrm{HONO}_{2}$ exclusively, but kinetic studies over a wide range of pressure (for the bath gas $\mathrm{M}$ ) and temperature conditions have shown that a secondary reaction product is also formed..$^{2-5}$ The secondary product was proposed to be peroxynitrous acid (HOONO), ${ }^{2,6,7}$ a weakly bound isomer of $\mathrm{HONO}_{2}$. Under atmospheric conditions, HOONO is formed reversibly,

$$
\mathrm{OH}+\mathrm{NO}_{2}+\mathrm{M} \rightleftarrows \mathrm{HOONO}+\mathrm{M},
$$

and is estimated to account for up to $20 \%$ of the yield from the $\mathrm{OH}+\mathrm{NO}_{2}$ reaction. ${ }^{5}$

$A b$ initio studies have predicted that there are at least two stable conformations of HOONO, ${ }^{5,8-10}$ namely, the transperp (tp) conformer with an extended open structure and the cis-cis (cc) conformer with a five-member ringlike structure.

\footnotetext{
a) On sabbatical leave (2004-2005) from the Department of Chemistry and Biochemistry, Swarthmore College, Swarthmore, PA 19081.

b) Author to whom correspondence should be addressed. Fax: (215) 5732112; electronic mail: milester@sas.upenn.edu
}

The latter has an intramolecular hydrogen bond between the terminal hydrogen and oxygen atoms, which increases the rigidity and stability of the cc conformer, and also has the effect of significantly shifting its $\mathrm{OH}$ stretching frequency to lower energy. As illustrated in Fig. 1, experiments have shown that the tp-conformer has a stability of 16.2(1) $\mathrm{kcal} \mathrm{mol}^{-1}$ relative to the $\mathrm{OH}+\mathrm{NO}_{2}$ asymptote, ${ }^{11}$ the cc conformer has a stability of $\sim 19.8 \mathrm{kcal} \mathrm{mol}^{-1}, 4,12$ and a substantial barrier (tp-cc) separates the two conformers. ${ }^{13}$ There has been considerable debate in the literature (as yet unresolved) as to whether or not there is a third stable conformer of HOONO in the cis-perp (cp) configuration. ${ }^{8,9,13-15}$ Nevertheless, there is ample evidence that torsional excitation of cc-HOONO can break the intramolecular hydrogen bond and thereby access cp-like configurations. ${ }^{12,16}$

Although HOONO was detected under matrix-isolation conditions some time ago, ${ }^{17,18}$ it eluded gas-phase spectroscopic detection until very recently. The cc-HOONO conformer has been subsequently observed under thermal flow cell conditions using infrared action spectroscopy in the first and second $\mathrm{OH}$ overtone regions, ${ }^{13,19,20}$ cavity ring down spectroscopy in the fundamental and first $\mathrm{OH}$ overtone regions, ${ }^{10,16}$ and pure rotational spectroscopy. ${ }^{21}$ The tpHOONO conformer has been characterized by this laboratory using infrared action spectroscopy in the first $\mathrm{OH}$ overtone region under jet-cooled conditions, ${ }^{11,22}$ and has also been detected using this same method under thermal conditions. ${ }^{13}$ The cc-HOONO conformer was not detected in the first overtone region under analogous jet-cooled conditions, ${ }^{11}$ because a combination of its lower $\mathrm{OH}$ over- 


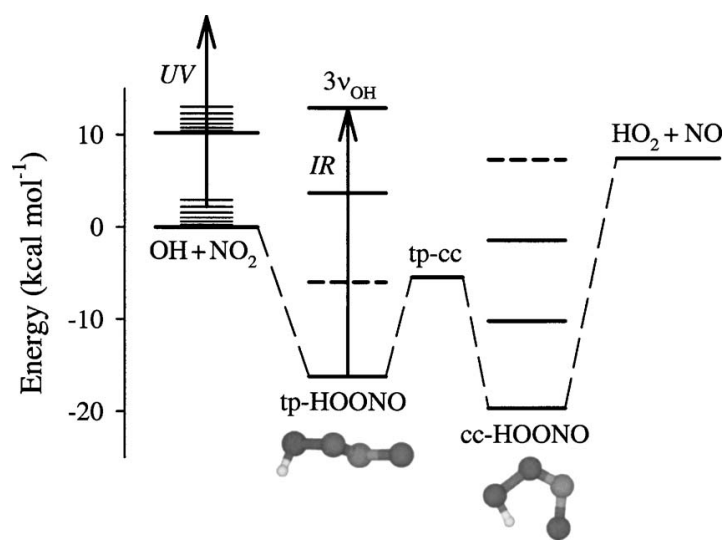

FIG. 1. Potential energy diagram for the trans-perp (tp) and cis-cis (cc) conformers of peroxynitrous acid (HOONO), illustrating the $\mathrm{OH}+\mathrm{NO}_{2}$ and $\mathrm{HO}_{2}+\mathrm{NO}$ asymptotes along with the tp-cc isomerization barrier. The second $\mathrm{OH}$ overtone of tp-HOONO is excited by the IR pump laser and the $\mathrm{OH}$ $(\nu=0)$ or $(\nu=1)$ fragments are detected with the UV probe laser. The previously observed HOONO vibrational transitions are marked with solid lines (Refs. 10, 11, 13, 16, 19, 20, and 22), while unobserved or tentatively assigned vibrational transitions are indicated as dashed lines (Ref. 20). The stability of tp-HOONO of 16.2(1) $\mathrm{kcal} \mathrm{mol}^{-1}$ is taken from Ref. 11, while that for cc-HOONO is obtained from Refs. 4 and 12 .

tone transition frequency, $6365 \mathrm{~cm}^{-1}$ (cc) vs $6971 \mathrm{~cm}^{-1}$ (tp), and greater binding energy prevents dissociation, which is required for action spectroscopy measurements. The ccHOONO overtone spectrum obtained under thermal conditions also exhibits a reduced quantum yield for features below $\sim 6940 \mathrm{~cm}^{-1}\left(19.8 \mathrm{kcal} \mathrm{mol}^{-1}\right){ }^{13}$ This skews the appearance of the action spectrum, suppressing lower energy features relative to hot bands originating from excited torsional levels that appear at higher frequency $\left(\sim 6935 \mathrm{~cm}^{-1}\right)$. $^{12,16}$

This paper extends our previous work ${ }^{11,22}$ by examining $\mathrm{HOONO}$ in the second $\mathrm{OH}$ overtone region under jet-cooled conditions. The overtone transition associated with the tp conformer is identified by its vibrational frequency and rotational band contour. Other aspects of the overtone spectrum provide detailed information on the transition dipole moment and the initial step of the intramolecular vibrational redistribution process that ultimately leads to dissociation. Finally, the quantum state distributions of the $\mathrm{OH}$ products resulting from first and second $\mathrm{OH}$ overtone excitation of tp-HOONO are thoroughly characterized and compared with the predictions of several commonly used statistical models.

\section{EXPERIMENTAL METHOD}

The second $\mathrm{OH}$ overtone transition of tp-HOONO is detected in a pulsed supersonic expansion using an IR pump-UV probe technique similar to that used previously for the first $\mathrm{OH}$ overtone transition. ${ }^{11,22}$ For the second overtone, IR excitation occurs at $0.98 \mu \mathrm{m}$ and leads to the dissociation of tp-HOONO. The $\mathrm{OH}$ fragments are then detected by UV laser-induced fluorescence. Two types of experiments are performed: (1) Infrared action spectra of tp-HOONO $\left(3 \nu_{\mathrm{OH}}\right)$ are recorded by scanning the IR pump laser with the UV laser fixed on a specific $\mathrm{OH}$ transition and (2) $\mathrm{OH}$ $\left(\nu, J_{\mathrm{OH}}\right)$ quantum state distribution is determined by tuning the UV probe laser to various $\mathrm{OH} A^{2} \Sigma^{+}-X^{2} \Pi$ transitions with the IR pump laser fixed on the tp-HOONO overtone transition.

The procedure for generating HOONO in a pulsed supersonic expansion has been described previously, ${ }^{11}$ and only a brief summary is given here. The vapor from nitric acid $\left(\mathrm{HONO}_{2}, 100 \%\right.$ fuming, Spectrum Laboratory Products, Inc.) is entrained in Ar carrier gas (80 psi) and then photolyzed with the $193 \mathrm{~nm}$ output of an ArF exciter laser (Lambda Physik, Complex 102). Photolysis takes place within a quartz capillary tube (Wilmad Labglass, Suprasil $300,0.5 \mathrm{~mm}$ (i.d.) $\times 5 \mathrm{~mm}$ (o.d.) $\times 10 \mathrm{~mm}$ length) attached to a solenoid pulsed valve assembly (Parker Hannifin, Series 9). The photolytically generated $\mathrm{OH}$ and $\mathrm{NO}_{2}$ radicals undergo three-body association reactions in the high-pressure environment of the quartz capillary tube, leading to regeneration of $\mathrm{HONO}_{2}$ as well as formation of the desired HOONO product. Most of the $\mathrm{OH}$ radicals are reacted away in flowing through the capillary when photolysis occurs close to the pulsed valve, significantly reducing the $\mathrm{OH}$ background relative to other photolysis positions. ${ }^{11}$ The newly formed HOONO and other species present in the gas mixture are subsequently cooled in the supersonic expansion.

Infrared radiation at $0.98 \mu \mathrm{m}$ is produced with a $\beta$ $-\mathrm{BaB}_{2} \mathrm{O}_{4}$ (BBO)-based optical parametric oscillator (OPO, Continuum Sunlite) pumped by the $355 \mathrm{~nm}$ output of an injection-seeded Nd: yttrium aluminum garnet (YAG) laser (Continuum Precision 9010, 6 ns pulse and $10 \mathrm{~Hz}$ repetition rate). The OPO has a $0.12 \mathrm{~cm}^{-1}$ bandwidth [full width at half maximum (FWHM)] and is typically stepped in $0.03 \mathrm{~cm}^{-1}$ increments for each IR scan. The idler output of the OPO has a pulse energy of $\sim 17 \mathrm{~mJ}$ at the desired wavelength.

The absolute frequency of the IR source is determined by taking a photoacoustic spectrum of $\mathrm{H}_{2} \mathrm{O}$ using the idler output of the OPO. The observed photoacoustic transitions are compared with well-documented $\mathrm{H}_{2} \mathrm{O}$ lines in this spectral region. ${ }^{23}$ Higher precision relative frequency markers are also generated by recording an etalon trace using a portion of the signal output form the OPO. The relative frequency scale is determined by linear interpolation between adjacent etalon fringes (free spectral range $=1.68 \mathrm{~cm}^{-1}$ ). Frequency calibrations are taken concurrently with each IR spectrum of HOONO.

The second overtone excitation of tp-HOONO provides sufficient energy to produce both $\mathrm{OH}(\nu=0)$ and $(\nu=1)$ fragments, which are separately probed using $A-X(1,0)$ and $(0,1)$ transitions, respectively. The UV probe beam is generated by frequency doubling (Continuum UVT) the output of a Nd:YAG-pumped dye laser (Continuum 7020 and ND 6000, $7 \mathrm{~ns}$ pulse and $20 \mathrm{~Hz}$ repetition rate). The UV radiation for the $(1,0)$ transition at $282 \mathrm{~nm}$ is obtained by operating the dye laser with Rhodamine 590 dye or Rhodamine 590/610 dye mixture, and that for the $(0,1)$ transition at $346 \mathrm{~nm}$ is achieved with LDS 698 dye. Typically, $\sim 1 \mathrm{~mJ} / \mathrm{cm}^{2}$ of UV radiation is passed into the vacuum chamber with each pulse. The UV laser is calibrated using well-known positions of the OH $A-X(1,0)$ or $(0,1)$ lines. $^{24,25}$

The IR pump and UV probe beams are counterpropagated into the vacuum apparatus, where they are spatially 
overlapped $1.0 \mathrm{~cm}$ (or $\sim 20$ nozzle diameters) downstream from the exit of the quartz capillary tube. This distance has been reduced from $1.5 \mathrm{~cm}$ in previous studies ${ }^{11,22}$ to increase the number density of $\mathrm{HOONO}$ in the laser interaction region. The IR-UV time delay is also reduced from 50 to $20 \mathrm{~ns}$ to make certain that there are no collisions between the IR excitation of HOONO and the arrival of the UV probe laser. The HOONO spectra are recorded with the IR beam focused to $\sim 3 \mathrm{~mm}$ diameter, with the UV beam unfocused but reduced to $\sim 1 \mathrm{~mm}$ diameter with an aperture.

The $\mathrm{OH}$ laser-induced fluorescence (LIF) signal originating from the laser interaction region is collected using $f / 1$ optics and detected with a photomultiplier tube (PMT, EMI 9813Q) positioned perpendicular to both the laser and supersonic expansion axes. Scattered laser light from the photolysis and UV probe lasers is removed by a long pass filter (Schott WG-280) and a bandpass filter (14 nm FWHM) centered at either $307 \mathrm{~nm}$ for the $\mathrm{OH} A-X(0,0)$ emission or $315 \mathrm{~nm}$ for the $(1,1)$ emission. Filter transmission curves were measured with a UV/V is spectrophotometer (Beckman-Coulter DU640) to take into account the transmission of the filters at the $\mathrm{OH} A^{2} \Sigma^{+}$emission wavelengths in the data analysis. The PMT signal is amplified, integrated over a $400 \mathrm{~ns}$ gate, and transferred to a laboratory computer for further analysis.

The IR pump laser $(10 \mathrm{~Hz})$ is present for every other UV probe laser pulse $(20 \mathrm{~Hz})$. The HOONO infrared spectra are recorded using an active background subtraction procedure. Any background signal arising from the UV laser alone is subtracted from the IR+UV signal on every other laser shot.

The $\mathrm{OH}$ product state distribution is examined for both $\nu=0$ and $\nu=1$ vibrational levels. More extensive studies are carried out for $\mathrm{OH}(\nu=0)$, where $Q_{1}, Q_{2}, P_{1}$, and $P_{2}$ (or $R_{1}$ and $R_{2}$ ) branches are measured on the $A-X(1,0)$ transition, whereas only the $Q_{1}$ branch of the $A-X(0,1)$ transition is probed for $\mathrm{OH}(\nu=1)$. These particular transitions have been chosen in order to examine the relative population of the $\mathrm{OH}$ fragments as a function of vibrational $(\nu)$, rotational $\left(J_{\mathrm{OH}}\right)$, spin-orbit $(\Omega)$, and lambda-doublet $(\Lambda)$ states. Neither $\Lambda$-doublet component, $\Pi\left(A^{\prime}\right)$, or $\Pi\left(A^{\prime \prime}\right)$, of the lowest rotational state, $\mathrm{OH}^{2} \Pi_{3 / 2}\left(\nu=0, J_{\mathrm{OH}}=3 / 2\right)$, could be probed due to its large background population in the supersonic expansion. In addition, the population in a few $\mathrm{OH}(\nu=0)$ rotational levels that are probed by the $A-X(1,0) Q_{1}(13 / 2)$, $Q_{2}(1 / 2)$, and $Q_{2}(7 / 2)$ lines cannot be distinguished due to overlapping transition frequencies. Finally, nearby weak satellite lines $\left(P_{21}\right.$ and $\left.Q_{21}\right)$ may partially overlap main branch lines $\left(Q_{1}\right.$ and $\left.R_{1}\right)$ for the lowest $J_{\mathrm{OH}} \cdot{ }^{24,25}$

For the $\mathrm{OH}$ product state data, the UV laser is fixed on a specific $\mathrm{OH}$ transition and the LIF signal is collected with the IR laser on then off (750 laser shots on then off) in three independent measurements that are separately averaged. The IR-induced signal is taken to be the difference between the averaged IR on and off values. The intensity observed for each $\mathrm{OH}$ product transition is scaled relative to a reference line in each vibrational state, namely, either the $A-X(1,0) Q_{1}(9 / 2)$ or $A-X(0,1) Q_{1}(5 / 2)$ line, which is recorded immediately before and after each transition in order to account for small variations in the experimental conditions. These particular reference lines are selected because of their optimal signal-to-background ratios.

We have improved our analysis procedures for converting saturated LIF intensities measured on various $\mathrm{OH}$ $A-X(1,0)$ or $(0,1)$ lines into ground $X^{2} \Pi(\nu=0$ or 1$)$ state populations. The improvements take into account the transmission properties of the bandpass filters used in collecting OH $A-X(1,1)$ or $(0,0)$ fluorescence as well as the total lifetime and fluorescence quantum yield of the emitting state. These changes were needed because unimolecular dissociation of tp-HOONO $\left(3 \nu_{\mathrm{OH}}\right)$ produces $\mathrm{OH} X^{2} \Pi$ fragments in a broad range of quantum states. Subsequent LIF detection then accesses a correspondingly broad range of $\mathrm{OH} A^{2} \Sigma^{+}$ $(\nu=0$ or 1) quantum states, some of which are subject to electronic predissociation. ${ }^{26,27}$ Other aspects of the conversion from saturated LIF intensities to populations are unchanged from prior studies. ${ }^{28,29}$

The improved procedures take into account the transmission of the bandpass filter $T\left(\lambda_{i}\right)$ at the emission wavelengths $\left(\lambda_{i}\right)$ from a particular upper state, $\mathrm{OH} A^{2} \Sigma^{+}\left(\nu^{\prime}, N^{\prime}, F^{\prime}\right)$. The fraction of the emission that is transmitted through the bandpass filter $T\left(\nu^{\prime}, N^{\prime}, F^{\prime}\right)$, is given by

$$
T\left(\nu^{\prime}, N^{\prime}, F^{\prime}\right)=\frac{\sum_{i} T\left(\lambda_{i}\right) A_{i}}{\sum_{i} A_{i}} .
$$

The summation index spans over the allowed transitions from the upper state, $i \equiv A^{2} \Sigma^{+}\left(\nu^{\prime}, N^{\prime}, F^{\prime}\right)$ $\rightarrow X^{2} \Pi\left(\nu^{\prime \prime}, J_{\mathrm{OH}}^{\prime \prime}, \Omega^{\prime \prime}, \Lambda^{\prime \prime}\right)$. The quantum labels $\nu^{\prime}, N^{\prime}$, and $F^{\prime}$ refer to vibration, rotation (neglecting spin), and spinrotation components of the excited $\mathrm{OH} A^{2} \Sigma^{+}$electronic state. ${ }^{24,30}$ In general, for a specific $\nu^{\prime}, N^{\prime}$ level in the $A^{2} \Sigma^{+}$ state, there are six emission lines associated with each $A-X\left(\nu^{\prime}, \nu^{\prime \prime}\right)$ vibronic transition. The emission coefficients $A_{i}$ associated with these transitions include Franck-Condon and Hönl-London factors. ${ }^{25}$

In addition, the improved analysis accounts for the total lifetime $\tau$, in this case arising from radiative decay and/or predissociation, as well as the fluorescence quantum yield $\Phi_{f}\left(\nu^{\prime}, N^{\prime}, F^{\prime}\right)$ of the $\mathrm{OH} A^{2} \Sigma^{+}$emitting state. The total lifetime affects the fraction of the fluorescence decay collected during integration of a boxcar gate running from time $t_{1}$ to $t_{2}$,

$$
G\left(\tau, t_{1}, t_{2}\right)=e^{-t_{1} / \tau}-e^{-t_{2} / \tau} .
$$

The intensity of fluorescence $I_{f}$ detected from a particular $\mathrm{OH} A^{2} \Sigma^{+}\left(\nu^{\prime}, N^{\prime}, F^{\prime}\right)$ state is given by

$$
I_{f} \propto G\left(\tau, t_{1}, t_{2}\right) \Phi_{f}\left(\nu^{\prime}, N^{\prime}, F^{\prime}\right) T\left(\nu^{\prime}, N^{\prime}, F^{\prime}\right),
$$

with the proportionality sign used to indicate other experimental factors that are unchanged for different upper states, such as the fraction of light impinging on the collection optics and the PMT detection efficiency. 


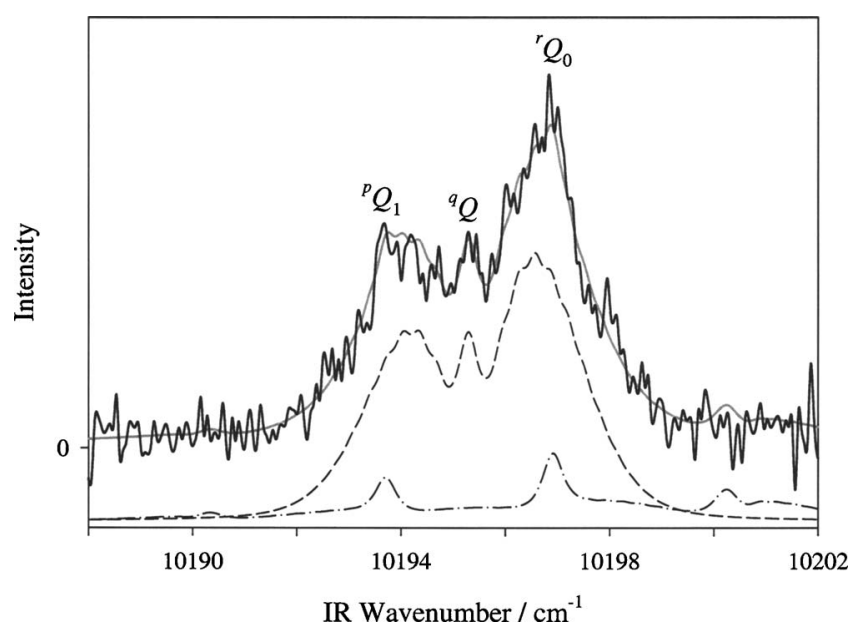

FIG. 2. Infrared action spectrum of the second $\mathrm{OH}$ overtone transition of tp-HOONO at $10195.32(5) \mathrm{cm}^{-1}$ (origin), recorded with the UV probe laser fixed on the $\mathrm{OH} A-X(1,0) Q_{1}(9 / 2)$ transition. The simulation of the rotational band contour (solid line) is generated from the rotational constants derived from a fit to the first $\mathrm{OH}$ overtone band. A least-squares fit of the intensity profile yielded a hybrid band type of $a: c=4.2(7): 1$, rotational temperature of $5.2(2) \mathrm{K}$, and a homogeneous linewidth of $0.44(12) \mathrm{cm}^{-1}$. The $a$-type (dashed line) and $c$-type (dot-dashed line) components of the simulation are also shown.

\section{RESULTS AND ANALYSIS}

\section{A. OH overtone excitation of tp-HOONO}

\section{Experimental spectrum and simulation}

The infrared action spectrum of tp-HOONO in the second $\mathrm{OH}$ overtone region is observed at $10195.32(5) \mathrm{cm}^{-1}$ (origin) under jet-cooled conditions. The action spectrum shown in Fig. 2 is obtained by scanning the IR laser with the UV laser detecting $\mathrm{OH}\left(\nu=0, J_{\mathrm{OH}}=9 / 2\right)$ fragments on the $A-X(1,0) Q_{1}(9 / 2)$ transition. This $\mathrm{OH}$ product channel yields the largest IR-induced signal $(S)$ relative to background $(B)$ from unreacted $\mathrm{OH}$ in the jet $(S / B \sim 1 / 2)$. The spectrum displayed in Fig. 2 is the sum of four scans, with each point resulting from $600 \mathrm{IR}$ laser shots. The second $\mathrm{OH}$ overtone transition of tp-HOONO is identified by its vibrational frequency and rotational band contour.

A Birge-Sponer plot has been constructed using the second $\mathrm{OH}$ overtone $\left(10195.3 \mathrm{~cm}^{-1}\right)$ and the previously reported first overtone $\left(6971.4 \mathrm{~cm}^{-1}\right)$ (Refs. 11 and 22) transitions of tp-HOONO in Fig. 3. The local mode behavior of the $\mathrm{OH}$ stretching mode of tp-HOONO is similar to that found for nitric $\operatorname{acid}^{31-35}$ and the $\mathrm{OH}$ radical itself, ${ }^{36}$ which are also displayed in Fig. 3. The harmonic frequency $\omega_{e}$ $=3747.5 \mathrm{~cm}^{-1}$ and anharmonicity $\omega_{e} x_{e}=87.3 \mathrm{~cm}^{-1}$ for tpHOONO are readily extracted from the Birge-Sponer plot. By contrast, the considerably lower $\mathrm{OH}$ stretch frequency $\left(\omega_{e}=3553.0 \mathrm{~cm}^{-1}\right)$ and increased anharmonicity $\left(\omega_{e} x_{e}\right.$ $=123.5 \mathrm{~cm}^{-1}$ ) of cc-HOONO, ${ }^{10,13}$ arising from its intramolecular hydrogen bond, distinguish its local mode behavior from the other species.

In addition, the rotational band contour of the second $\mathrm{OH}$ overtone transition of tp-HOONO (Fig. 2) closely resembles that of the first overtone transition. ${ }^{11,22}$ In both cases, the band contour is that of a near-prolate asymmetric top with prominent contributions from both $a$-and $c$-type

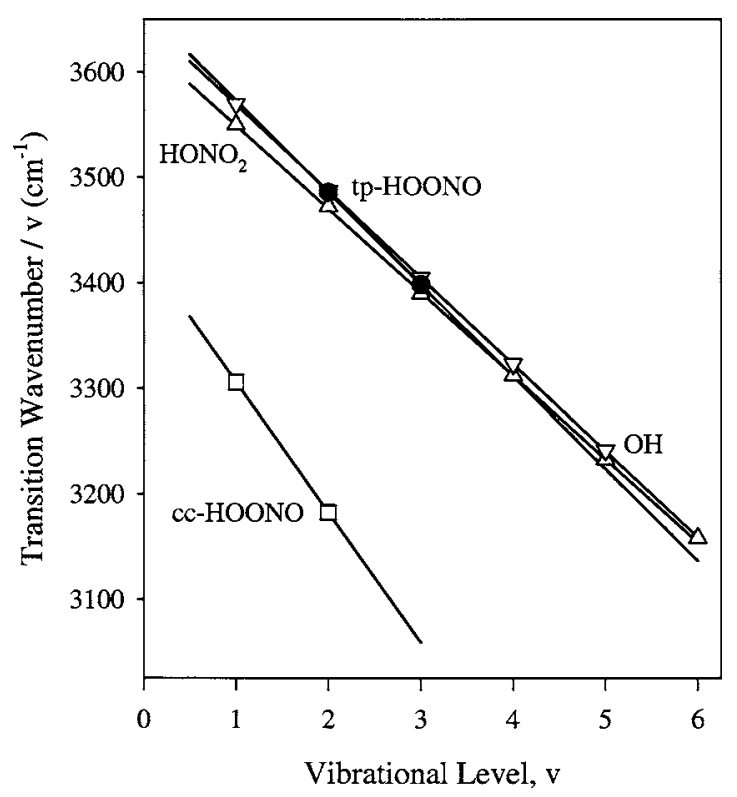

FIG. 3. Birge-Sponer plot for the OH stretching modes of tp-HOONO (filled circles), $\mathrm{HONO}_{2}$ (up triangles), and the $\mathrm{OH}$ radical (down triangles), showing the similarity of their local mode behavior. The cc-HOONO conformer (squares) is distinctly different due to its intramolecular hydrogen bond. The $\mathrm{OH}$ stretch transition frequencies are taken from this laboratory's work (Refs. 11 and 22) for tp-HOONO and Refs. 10, 13, and 31-36 for the other species.

transitions (and negligible $b$-type component). The ${ }^{q} Q$ branch of the $a$-type (parallel) transition at $10195.3 \mathrm{~cm}^{-1}$ gives rise to the peak in the central region of the band, while the $c$-type (perpendicular) transition $Q$ branches, ${ }^{p} Q_{1}$ at $10193.7 \mathrm{~cm}^{-1}$ and ${ }^{r} Q_{0}$ at $10196.9 \mathrm{~cm}^{-1}$, contribute to the peaks at the edges of the band (along with the $P$ and $R$ branches of the $a$-type transition). The $Q$-branch labels refer to $\Delta K_{a}$ (superscript) and $K_{a}^{\prime \prime}$ (subscript) in the prolate symmetric top limit.

A simulation generated using the rotational constants derived for the ground and upper $\left(2 \nu_{\mathrm{OH}}\right)$ vibrational states from the first $\mathrm{OH}$ overtone transition of tp-HOONO (Ref. 11) is superimposed on the experimental data for the second overtone transition in Fig. 2. The $a$ - and $c$-type components of the simulation are also shown in Fig. 2. The remarkable agreement identifies the band at $10195.3 \mathrm{~cm}^{-1}$ as originating from tp-HOONO. There is no observable change in the rotational constants for tp-HOONO $\left(3 \nu_{\mathrm{OH}}\right)$ as compared with $2 \nu_{\mathrm{OH}}$ at the level of detail that can be extracted from the experimental spectrum. Indeed, the rotational constants previously derived from the first overtone transition had already indicated minimal structural change in tp-HOONO upon vibrational excitation of the $\mathrm{OH}$ stretching mode. ${ }^{11}$

The spectral simulation also depends on several other parameters, namely, the Lorentzian linewidth, rotational temperature, and the $a$ - to $c$-type transition ratio. These parameters are determined in a least-squares fitting procedure to match the intensity profile and linewidth of the experimental spectrum. Although all three of these parameters are sensitive to even partial saturation in the spectrum, this effect is expected to be negligible for the second $\mathrm{OH}$ overtone transition because of its weak oscillator strength (see below). Nevertheless, there is substantial homogeneous line broaden- 
ing from some other source that is much greater than the OPO bandwidth of $0.12 \mathrm{~cm}^{-1}$. The best fit results in a rotational temperature of $5.2(2) \mathrm{K}$, a Lorentzian linewidth of $0.44(12) \mathrm{cm}^{-1}$, and an $a: c$ ratio of $4.2(7): 1$. The uncertainties $(1 \sigma)$ reflect the significant correlation between the fitted parameters. The $a: c$ ratio is considerably different than the 1.2(1): 1 ratio observed for the first $\mathrm{OH}$ overtone transition, ${ }^{11}$ indicating a change in the direction of the transition dipole moment with increasing $\mathrm{OH}$ stretch excitation (see next section). The apparent linewidth is about a factor of two times larger than seen for the first overtone transition where $\Gamma=0.195(4) \mathrm{cm}^{-1} \cdot{ }^{11}$ As will be discussed later, the homogeneous line broadening is attributed to intramolecular vibrational redistribution (IVR). ${ }^{11} \mathrm{~A}$ direct measurement of the tp-HOONO $\left(3 \nu_{\mathrm{OH}}\right)$ dissociation lifetime in the time domain is precluded by the laser pulse width (6 ns).

\section{Transition dipole moment}

The second $\mathrm{OH}$ overtone transition of tp-HOONO is observed to be a hybrid band with a 4.2(7):1 ratio of the $a$ - to $c$-type components of the transition moment. This $a: c$ ratio indicates that the transition dipole lies $49^{\circ}$ off of the $\mathrm{OH}$ bond axis. In contrast, the $a: c$ ratio determined for the first overtone transition of 1.2(1):1 reveals that the transition dipole points $35^{\circ}$ off of the $\mathrm{OH}$ bond axis. The $14^{\circ}$ change in the direction of the transition dipole moment results in more than a threefold change in the $a: c$ intensity ratio due to trigonometric considerations. In both cases, the result is significantly different from the bond dipole approximation, ${ }^{37}$ which assumes that the transition dipole lies along the $\mathrm{OH}$ bond axis and would give rise to a 1 to 12 ratio of the $a$ - to $c$-type components. The orientation of the transition dipole moment for the $\mathrm{OH}$ overtone transitions presumably reflects changes in the charge distribution of the tp-HOONO molecule upon $\mathrm{OH}$ stretch excitation. ${ }^{38}$

The relative oscillator strength for the first and second $\mathrm{OH}$ overtone transitions of tp-HOONO has also been determined by comparing the signal intensities of the strongest peak in each IR spectrum while probing the $\mathrm{OH}$ products on the $A-X(1,0) Q_{1}(9 / 2)$ line. The IR pump beam at 0.98 or $1.4 \mu \mathrm{m}$ was carefully aligned with the UV probe beam, which was unchanged while switching between the IR sources. For these measurements, the UV beam was kept slightly larger than either IR beam. Next, spectral simulations were used to convert the measured intensity of the strongest peak in each IR spectrum to the integrated intensity of the vibrational band. The integrated band intensities were then changed to relative oscillator strength by taking into account the photon flux (pulse power divided by transition frequency). Finally, the fraction of $\mathrm{OH}$ products in the specified product state, $\nu=0, J_{\mathrm{OH}}=9 / 2, \Omega=3 / 2, \Pi\left(A^{\prime \prime}\right)$, was obtained from the statistical calculations for dissociation of tpHOONO $\left(3 \nu_{\mathrm{OH}}\right)$ and $\left(2 \nu_{\mathrm{OH}}\right),{ }^{39}$ since the $\mathrm{OH}$ products are spread over many more internal energy states for $3 \nu_{\mathrm{OH}}$ than $2 \nu_{\mathrm{OH}}$. The net result is that the oscillator strength for the second $\mathrm{OH}$ overtone transition of tp-HOONO is found to be $\sim 14$ times weaker than that for the first overtone transition. This ratio neglects the unobserved $\mathrm{HO}_{2}+\mathrm{NO}$ product channel for tp-HOONO $\left(3 \nu_{\mathrm{OH}}\right){ }^{40}$

\section{B. OH product state distribution \\ 1. Experimental rotational distribution}

Information about the unimolecular decay dynamics of tp-HOONO $\left(3 \nu_{\mathrm{OH}}\right)$ is obtained from the nascent quantum state distribution of the $\mathrm{OH}(\nu=0)$ and $(\nu=1)$ products. For these experiments, the infrared laser is fixed on the most intense peak in the tp-HOONO second $\mathrm{OH}$ overtone spectrum at $10196.9 \mathrm{~cm}^{-1}$, while the UV laser is tuned to various lines of the $\mathrm{OH} A-X(1,0)$ and $(0,1)$ transitions to determine the relative population of the $\mathrm{OH}$ products in each internal energy state. The excess energy available for internal excitation and/or translational recoil of the $\mathrm{OH}+\mathrm{NO}_{2}$ products is obtained by subtracting the previously determined binding energy for tp-HOONO $D_{0}=5667(38) \mathrm{cm}^{-1}$ (Ref. 11) from the photon energy, yielding $E_{\text {avail }}=4530(38) \mathrm{cm}^{-1}$.

As shown in Fig. 4, the $\mathrm{OH}(\nu=0)$ product state distribution resulting from $3 \nu_{\mathrm{OH}}$ excitation peaks at low rotational states in each spin-orbit $(\Omega)$ manifold, $J_{\mathrm{OH}}=7 / 2$ (or $9 / 2$ ), $\Omega=3 / 2$, and $J_{\mathrm{OH}}=9 / 2, \Omega=1 / 2$ with internal energies $E_{\mathrm{OH}}$ $=202$ (or 355$) \mathrm{cm}^{-1}$ and $E_{\mathrm{OH}}=608 \mathrm{~cm}^{-1}$, respectively, and falls off smoothly with increasing rotational excitation $\left(J_{\mathrm{OH}}\right)$. One of the most populated states, $J_{\mathrm{OH}}=9 / 2, \Omega=3 / 2, \Pi\left(A^{\prime \prime}\right)$, served as a reference channel. The $\mathrm{OH}\left(\nu=0, J_{\mathrm{OH}}\right)$ distribution appears to extend to the energetic limit of $4530(38) \mathrm{cm}^{-1}$ in both spin-orbit manifolds. The highest $J_{\mathrm{OH}}$ levels are probed on $\mathrm{OH} A-X(1,0)$ transitions that access predissociative rotational levels $\left(N^{\prime}>13\right)$ of the $\mathrm{OH} A^{2} \Sigma^{+}$ $\left(\nu^{\prime}=1\right)$ state. $^{26,27}$ The improved analysis procedures (Sec. II) take into account the total lifetime and fluorescence quantum yield of the emitting state. ${ }^{25}$ The observed $\mathrm{OH}$ $(\nu=0)$ population distribution could not be normalized because a few transitions could not be measured. Instead, a normalization constant was chosen that gives the best agreement with all three statistical models (Fig. 4). The $\mathrm{OH}(\nu$ $=0)$ product state distribution appears to be statistical with no lambda-doublet $(\Lambda)$ or spin-orbit $(\Omega)$ propensities, as will be demonstrated in the next section when the experimental distribution is compared with several statistical models.

Significantly less population is detected for vibrationally excited $\mathrm{OH} \quad(\nu=1)$ products. These products contain $3568.5 \mathrm{~cm}^{-1}$ of vibrational energy, leaving at most $962(38) \mathrm{cm}^{-1}$ available for rotational and/or spin-orbit excitation of the $\mathrm{OH}$ fragment. In this case, the most populated $J_{\mathrm{OH}}=5 / 2, \Omega=3 / 2, \Pi\left(A^{\prime \prime}\right)$ state with $E_{\mathrm{OH}}=3649 \mathrm{~cm}^{-1}$ served as the reference channel. The population in this product channel is approximately 30 times smaller than that found for the $\mathrm{OH}(\nu=0)$ reference channel, as elaborated below. Such small populations naturally have relatively large uncertainties associated with them. As a result, we were not able to obtain a meaningful product rotational distribution for $\mathrm{OH}$ $(\nu=1)$. Instead, we focused on a careful measurement of the relative population of the reference channel for $\nu=1$ compared with that for $\nu=0$. This provides an important benchmark for testing various statistical theories.

Also shown in Fig. 4 is the $\mathrm{OH}(\nu=0)$ product state distribution observed following dissociation of tp-HOONO $\left(2 \nu_{\mathrm{OH}}\right)$, which is reproduced from Ref. 11. The same statistical models are applied to this unimolecular decay process, 


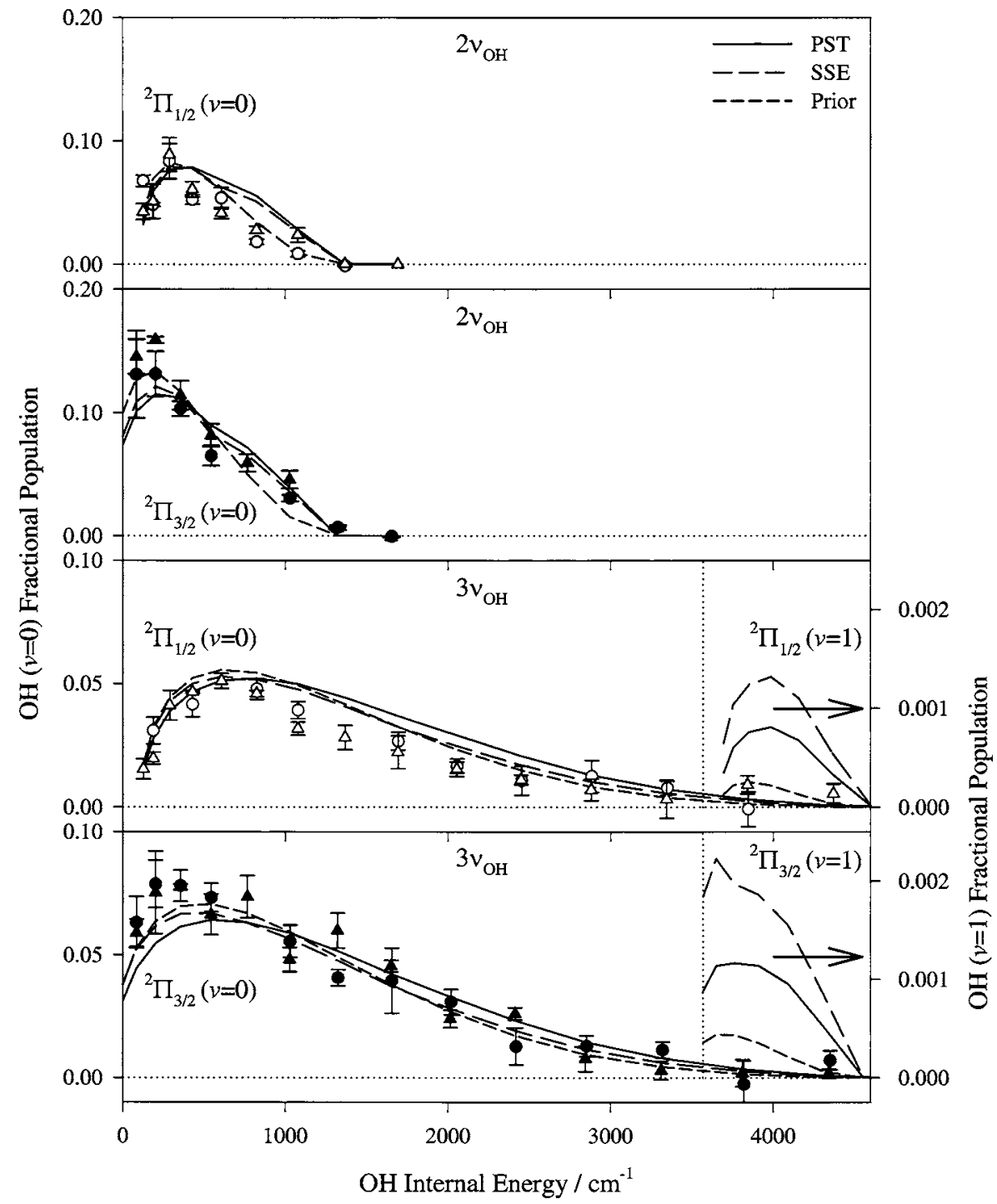

FIG. 4. Internal energy distribution of the $\mathrm{OH}\left(\nu=0, J_{\mathrm{OH}}\right)$ products observed in the excited ${ }^{2} \Pi_{1 / 2}$ (open symbols) and ground ${ }^{2} \Pi_{3 / 2}$ (filled symbols) spin-orbit manifolds following dissociation of tp-HOONO $\left(2 \nu_{\mathrm{OH}}\right)$, top panels (from Ref. 11), and $\left(3 \nu_{\mathrm{OH}}\right)$, bottom panels. The $\Pi\left(A^{\prime \prime}\right)$ and $\Pi\left(A^{\prime}\right)$ $\Lambda$-doublet components are distinguished by circle and triangle symbols, respectively. The smooth curves through the experimental data are obtained from three different statistical models, namely, a prior distribution (prior), phase-space theory (PST), and the separate statistical ensembles (SSE) model. For tp-HOONO $\left(3 \nu_{\mathrm{OH}}\right)$, the three statistical models predict extremely small $\mathrm{OH}\left(\nu=1, J_{\mathrm{OH}}\right)$ populations (enhanced $40 \times$ and referenced to the right axis) in the two spin-orbit manifolds.

extending our previous investigation of this process. In this case $E_{\text {avail }}$ is $1304(38) \mathrm{cm}^{-1}$, as determined from a fit to a microcanonical statistical distribution constrained only by the energy available to the products (prior distribution). ${ }^{11}$ An equivalent available energy is obtained from the highest observed $\mathrm{OH}$ product state, $J_{\mathrm{OH}}=17 / 2, \Omega=3 / 2$, with $E_{\mathrm{OH}}=1324.3 \mathrm{~cm}^{-1} .11$

\section{Vibrational branching ratio}

The relative LIF intensities of the $\mathrm{OH} A-X$ lines used to probe the $\nu=0$ and $\nu=1$ reference channels following dissociation of tp-HOONO $\left(3 \nu_{\mathrm{OH}}\right)$, namely, $\mathrm{OH}$ $A-X(1,0) Q_{1}(9 / 2)$ and $(0,1) Q_{1}(5 / 2)$ lines, were carefully measured under similar experimental conditions. Converting these intensities into relative populations requires a detailed analysis since different vibronic transitions were utilized. In addition, several experimental parameters had to be changed, most importantly the bandpass filter used for collecting fluorescence.

The LIF intensity data was recorded with $\sim 1 \mathrm{~mJ} / \mathrm{cm}^{2}$ per pulse of UV radiation in both cases, which is more than enough to saturate the $\mathrm{OH} A-X(1,0) Q_{1}(9 / 2)$ and $(0,1) Q_{1}(5 / 2)$ transitions. As a result, it is not necessary to include their relative transition probabilities in the analysis that follows. Instead, one can assume in each case that half of the population in the lower state is transferred to the upper state.

On the other hand, the fluorescence emission from the upper states of these transitions, $\mathrm{OH} A^{2} \Sigma^{+}\left(\nu^{\prime}=1, N^{\prime}=4\right)$ and $\left(\nu^{\prime}=0, N^{\prime}=2\right)$, is detected with different efficiencies, and this must be taken into account (see Sec. II). The bandpass filters were selected to transmit emission primarily from diagonal transitions $\mathrm{OH} A-X(1,1)$ or $(0,0)$ at 315 or $309 \mathrm{~nm}$, respectively. These filters have somewhat different transmission properties at the relevant wavelengths. In addition, the upper states of the reference lines have slightly different lifetimes, but neither are subject to electronic predissociation and both have unit fluorescence quantum yields. ${ }^{25}$

The relative LIF intensities for the $\mathrm{OH} A-X(1,0)$ $Q_{1}(9 / 2)$ and $(0,1) Q_{1}(5 / 2)$ lines were measured following second $\mathrm{OH}$ overtone excitation of tp-HOONO, and converted to relative population of the $\mathrm{OH} X^{2} \Pi_{3 / 2}$ $\left(\nu=0, J_{\mathrm{OH}}=9 / 2\right)$ and $\left(\nu=1, J_{\mathrm{OH}}=5 / 2\right)$ levels using the procedure outlined above. A ratio of $\sim 0.037$ is obtained for the relative population in the $\nu=1$ to $\nu=0$ reference channels. 


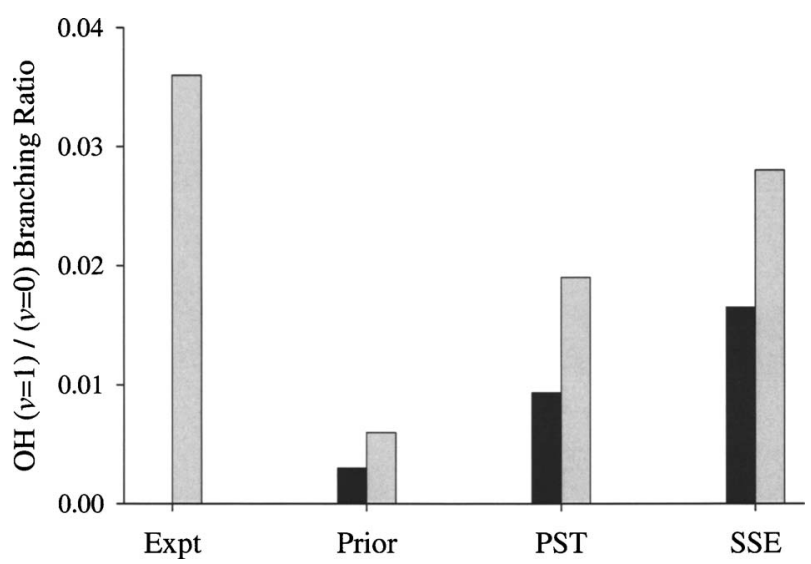

FIG. 5. Vibrational branching ratio for $\mathrm{OH}(\nu=1)$ to $(\nu=0)$ products from the experiment and various statistical models following dissociation of tpHOONO $\left(3 \nu_{\mathrm{OH}}\right)$. The gray bars are the experimental measurement and model predictions for the relative population of the reference channels, namely, $\mathrm{OH}\left(\nu=1, J_{\mathrm{OH}}=5 / 2, \Omega=3 / 2\right)$ and $\mathrm{OH}\left(\nu=0, J_{\mathrm{OH}}=9 / 2, \Omega=3 / 2\right)$. The black bars are the statistical model predictions for the $\mathrm{OH}(\nu=1)$ to $(\nu=0)$ ratio after summing over product rotational and fine-structure states.

This ratio is plotted as a bar graph in Fig. 5 and compared with the results of various statistical models in the next section.

\section{STATISTICAL MODELS FOR tp-HOONO DISSOCIATION}

\section{A. Statistical model formulation}

In a previous publication on the unimolecular decay dynamics of tp-HOONO $\left(2 \nu_{\mathrm{OH}}\right),{ }^{11}$ we compared the distribution of $\mathrm{OH}(\nu=0)$ fragments over rotational and spin-orbit states to the predictions of a prior distribution, ${ }^{41,42}$ and found excellent agreement. We now extend our examination of statistical models for dissociation of tp-HOONO by considering both phase-space theory (PST) and the separate statistical ensembles (SSE) model. ${ }^{43,44}$ In this new work, we apply the latter two models to the previously reported $\mathrm{OH}$ fragment distributions that result from excitation of the first $\mathrm{OH}$ overtone in tp-HOONO and all three models to the fragments that result from second overtone excitation. In the calculations, we specifically take into account the quantized nature of the $\mathrm{OH}$ and $\mathrm{NO}_{2}$ vibrations and rotations, but treat the relative translational energy as a classical function. The energies of the $\mathrm{OH}$ rotational states for both vibrational levels $(\nu=0,1)$ and both spin-orbit states $(\Omega=1 / 2,3 / 2)$ are taken from the work of Dieke and Crosswhite. ${ }^{24}$ We treat the $\mathrm{NO}_{2}$ fragment as an anharmonic oscillator, using the vibrational constants of Bist and Brand. ${ }^{45}$ As a near-prolate symmetric top $(\kappa=$ $-0.994)$, we model the $\mathrm{NO}_{2}$ rotations with symmetric top energy levels, invoking ${ }^{16} \mathrm{O}$ nuclear-spin statistics to eliminate the degeneracy of rotational levels with $K>0$ and exclude levels for which $K=0$ and $J=$ odd.

In the prior distribution, the $\mathrm{OH}$ product states are assumed to be populated with equal probability, subject only to an energy constraint. ${ }^{41,42}$ The probability of populating specific $\mathrm{OH}\left(\nu, J_{\mathrm{OH}}, \alpha_{\mathrm{OH}}\right)$ and $\mathrm{NO}_{2}\left(\nu_{\mathrm{NO}_{2}}, J_{\mathrm{NO}_{2}}, \alpha_{\mathrm{NO}_{2}}\right)$ product states at a given total energy is represented by

$$
\begin{gathered}
P\left(\nu, J_{\mathrm{OH}}, \alpha_{\mathrm{OH}}, \nu_{\mathrm{NO}_{2}}, J_{\mathrm{NO}_{2}}, \alpha_{\mathrm{NO}_{2}} \mid E_{\mathrm{avail}}\right) \\
=C\left(2 J_{\mathrm{OH}}+1\right)\left(2 J_{\mathrm{NO}_{2}}+1\right) E_{t}^{1 / 2},
\end{gathered}
$$

with

$$
E_{t}=E_{\text {avail }}-E_{\mathrm{OH}}-E_{\mathrm{NO}_{2}} .
$$

Here, $\left(2 J_{\mathrm{OH}}+1\right)$ is the degeneracy of $\mathrm{OH}$ rotational states, $\left(2 J_{\mathrm{NO}_{2}}+1\right)$ is the degeneracy of $\mathrm{NO}_{2}$ rotational states, and $E_{t}^{1 / 2}$ is the density of translational states associated with the relative motion of the separating $\mathrm{OH}$ and $\mathrm{NO}_{2}$ fragments. The factor $C$ is simply a normalization constant. The index $\nu$ is the $\mathrm{OH}$ vibrational quantum number and $\alpha_{\mathrm{OH}}$ refers to the additional quantum labels that are needed to characterize the $\mathrm{OH}$ fragment, namely, its spin-orbit $(\Omega)$ and lambda-doublet $(\Lambda)$ state. Similarly, the index $\alpha_{\mathrm{NO}_{2}}$ is used to account for the relevant quantum numbers of the $\mathrm{NO}_{2}$ symmetric top $\mathrm{N}_{\mathrm{NO}_{2}}$ and $K_{\mathrm{NO}_{2}}$. The quantum number $\nu_{\mathrm{NO}_{2}}$ refers to the vibrational degrees of freedom of the $\mathrm{NO}_{2}$ fragment. The vertical line separating $E_{\text {avail }}$ from other parameters indicates that the available energy is a constraint on the distribution. In the experiment, we examine the probability of the $\mathrm{OH}$ products being formed in a given quantum state $\left(\nu, J_{\mathrm{OH}}, \alpha_{\mathrm{OH}}\right)$. As a result, we sum the prior distribution given above over the unobserved $\mathrm{NO}_{2}$ rotational and/or vibrational states. The resulting $\mathrm{OH}$ distribution is given by

$$
\begin{aligned}
& P\left(\nu, J_{\mathrm{OH}}, \alpha_{\mathrm{OH}} \mid E_{\text {avail }}\right) \\
& \quad=C\left(2 J_{\mathrm{OH}}+1\right) \sum_{\nu_{\mathrm{NO}_{2}}, J_{\mathrm{NO}_{2}}, \alpha_{\mathrm{NO}_{2}}}\left(2 J_{\mathrm{NO}_{2}}+1\right) E_{t}^{1 / 2} .
\end{aligned}
$$

In the PST calculations, ${ }^{34,42,43}$ we apply the additional constraint that the total angular momentum of the system must be conserved. PST also differs from a prior distribution in the treatment of the translational density of states, as documented in the literature. ${ }^{43}$ The conservation of total angular momentum results in a significant decrease in the number of states that can be populated. Specifically, we assume throughout the calculations that $J=4$, which is the approximate mean of the HOONO rotational states comprising the ${ }^{r} Q_{0}$ branch and populated at $3-5 \mathrm{~K}$ in the free jet expansion. (The calculated fragment distributions are nearly the same for total $J=0-10$, a range that encompasses more than $95 \%$ of the tp-HOONO molecules excited on the ${ }^{r} Q_{0}$ branch.) The total angular momentum $\mathbf{J}$ is the vector sum of the fragment angular momenta and the orbital angular momentum of the recoiling fragments $\mathbf{L}$,

$$
\mathbf{J}=\mathbf{J}_{\mathrm{OH}}+\mathbf{J}_{\mathrm{NO}_{2}}+\mathbf{L} \text {. }
$$

In the PST calculations, we sum over $\mathbf{L}$ and all of the energetically accessible $\mathrm{NO}_{2}$ states for each $\mathrm{OH}$ rotational state, subject to the conservation of angular momentum. We further restrict the possible values of the orbital angular momentum by calculating the height of the centrifugal barrier that arises from modeling the $\mathrm{OH}-\mathrm{NO}_{2}$ attraction as a simple $1 / R^{6}$ interaction, where $R$ is the center-of-mass distance between the $\mathrm{OH}$ and $\mathrm{NO}_{2}$ fragments. In this case, the height of the centrifugal barrier $V_{\max }$ is given by 


$$
V_{\max }=\frac{[L(L+1)]^{3 / 2} \hbar^{3}}{3 \sqrt{6} \mu^{3 / 2} C_{6}^{1 / 2}} .
$$

We have adopted the value of the $C_{6}$ coefficient that was found by Sinha et al. ${ }^{34}$ to reproduce the $\mathrm{OH}$ product state distribution that results from overtone-induced dissociation of nitric acid at $300 \mathrm{~K}$. (Our PST calculations are insensitive to this value, presumably because the restriction to a low value of total $J$ reduces the range of possible values of the orbital angular momentum and thus the importance of the centrifugal barrier in moderating the dissociation dynamics.) The state count corresponding to a particular $\mathrm{OH}$ state $\left(\nu, J_{\mathrm{OH}}, \alpha_{\mathrm{OH}}\right)$ excludes any set of values of $\left(\nu_{\mathrm{NO}_{2}}, J_{\mathrm{NO}_{2}}, \alpha_{\mathrm{NO}_{2}}\right)$ with available energy that is insufficient to surmount the centrifugal barrier.

We have also considered the predictions of phase-space theory in assessing the importance of the competing NO $+\mathrm{HO}_{2}$ dissociation channel following $3 \nu_{\mathrm{OH}}$ excitation. ${ }^{46}$ For this calculation, we have considered $\mathrm{HO}_{2}$ to be a prolate symmetric top $(\kappa=-0.994),{ }^{47}$ though in this case there are no nuclear-spin restrictions on the allowed rotational states. We also utilize the known vibrational fundamental frequencies of $\mathrm{HO}_{2}$ and the well-determined rotational constants of NO. ${ }^{48,49}$

The SSE approach to unimolecular dissociation is a variant on phase-space theory proposed initially by Wittig et $a l^{44}$ to account for the frequent observation that phasespace theory underestimates the degree of fragment vibrational excitation while overestimating the fragment rotational excitation. In this approach, the vibrational distributions in the products are determined by considering a restricted region of phase space that corresponds only to the vibrational degrees of freedom that have "disappeared" along the dissociation reaction coordinate. This is equivalent to assuming that the rotational degrees of freedom of the parent do not contribute to the density of states that determines the product vibrational distribution. For the case of HOONO dissociating to $\mathrm{OH}+\mathrm{NO}_{2}$, the parent has nine vibrational degrees of freedom and three rotational degrees of freedom. In the products, there are four vibrational and five rotational degrees of freedom, along with three translational degrees of freedom. In a phase-space theory calculation of, for example, the $\mathrm{NO}_{2}$ vibrational distribution, we count the number of energetically accessible states, subject to the conservation of energy and the limitations imposed by the centrifugal barrier. In the classical (high-energy) limit, the density of rotational and translational states for this set of fragments (and $J \rightarrow 0$ ) will vary as $\left(E_{\text {avail }}-E_{\mathrm{vib}}\right)^{2}$, where $E_{\text {avail }}$ is the energy available for disposal into the fragment internal and/or translational degrees of freedom and $E_{\mathrm{vib}}$ is the $\mathrm{NO}_{2}$ vibrational energy. In a SSE calculation, it is only the five "disappearing" vibrational degrees of freedom that contribute to the fragment vibrational distribution. This five-dimensional density-of-states function varies more slowly, as $\left(E_{\text {avail }}-E_{\text {vib }}\right)^{3 / 2}$. Thus excited fragment vibrational states will have higher population than in a phase-space theory calculation. By conservation of energy, the corresponding fragment rotational degrees of freedom must contain a smaller fraction of the available energy.

\section{B. Statistical model predictions}

The three statistical models (PST, SSE, and prior) predict remarkably similar $\mathrm{OH}(\nu=0)$ product state distributions following first $\mathrm{OH}$ overtone excitation and also similar distributions following second $\mathrm{OH}$ overtone excitation of tpHOONO as shown in Fig. 4. For both $2 \nu_{\mathrm{OH}}$ and $3 \nu_{\mathrm{OH}}$ excitations, the calculated distributions exhibit a trend of increasing population with rotational excitation at low $J_{\mathrm{OH}}$ that can be attributed to the increasing degeneracy of the rotational states. The population distributions then follow a rapid decrease (for $2 \nu_{\mathrm{OH}}$ ) or a more gradual decrease (for $\left.3 \nu_{\mathrm{OH}}\right)$ with increasing rotational excitation as energy restrictions, $E_{\text {avail }}=1304 \mathrm{~cm}^{-1}$ (for $2 \nu_{\mathrm{OH}}$ ) and $4530 \mathrm{~cm}^{-1}$ (for $\left.3 \nu_{\mathrm{OH}}\right)$, overtake the degeneracy factor. The angular momentum constraint associated with the PST and SSE models does not appreciably affect the product state distribution or its fall off at high $J_{\mathrm{OH}}$. The two spin-orbit states follow the same population distribution after accounting for the degeneracy of the states, and the two $\Lambda$-doublet components of each rotational level have similar populations. The PST calculations by Matthews and Sinha for tp-HOONO $\left(2 \nu_{\mathrm{OH}}\right)$ shown in Fig. 6 of Ref. 12 differ slightly from the present work in that they average over a thermal $(300 \mathrm{~K})$ distribution of initial HOONO states, rather than the limited HOONO rotational states populated at 3-5 K.

All the three statistical models indicate that vibrationally excited $\mathrm{OH}$ is a very minor channel in the dissociation of tp-HOONO $\left(3 \nu_{\mathrm{OH}}\right)$ with less than $2 \%$ of the $\mathrm{OH}$ products formed in $\nu=1$. However, the models differ in the fractional populations in $\mathrm{OH}(\nu=1)$ (Fig. 4, note the $40 \times$ magnification) as well as the $\mathrm{OH}(\nu=1) /(\nu=0)$ product branching ratios (Fig. 5). As expected from the formulation, ${ }^{44}$ the SSE model predicts the largest fractional population for $\mathrm{OH}$ $(\nu=1)$ and product branching ratio, followed by PST and then the prior distribution. The rotational distribution for the $\mathrm{OH}(\nu=1)$ products peaks at low $J_{\mathrm{OH}}$ and then falls off rapidly due to the very limited energy available for rotational and/or spin-orbit excitation $\left(962 \mathrm{~cm}^{-1}\right)$. For very low $J_{\mathrm{OH}}$ only, the $\mathrm{NO}_{2}$ product can be released with bending excitation $\left(742 \mathrm{~cm}^{-1}\right)$, creating a small bump in the calculated product state distribution.

Interestingly, the unobserved $\mathrm{HO}_{2}+\mathrm{NO}$ product channel is predicted to be significant upon the dissociation of tpHOONO $\left(3 \nu_{\mathrm{OH}}\right)$ with $21.5 \%$ of the total products. The statistical calculations (PST) indicate that the lower energy $\mathrm{OH}+\mathrm{NO}_{2}$ channel will be favored over the higher energy $\mathrm{HO}_{2}+\mathrm{NO}$ channel $\left(+7.5 \mathrm{kcal} \mathrm{mol}^{-1}\right)$ by a factor of 3.66 . This suggests alternate detection schemes for HOONO using action spectroscopy.

\section{Comparison of results from experiment and statistical models}

In general, the experimental $\mathrm{OH}(\nu=0)$ product state distributions observed following first and second $\mathrm{OH}$ overtone excitation of tp-HOONO can be termed "statistical," since there is very good agreement with the statistical models (Fig. 4). ${ }^{11}$ However, there are noticeable differences; specifically, the experimental distributions appear to be rotationally 
colder particularly at low $J_{\mathrm{OH}}$ than the predictions of all three statistical models. The origin of this discrepancy is not known. It cannot be attributed to the neglect of angular momentum conservation in the prior model, ${ }^{41,42}$ since this constraint is explicitly included in the PST and SSE models. ${ }^{43,44}$ While it has been previously noted that PST tends to favor rotational over vibrational excitation of products in unimolecular dissociation processes, the SSE model was developed to address this issue, ${ }^{44}$ yet it does not give better agreement with the experimental data at low $J_{\mathrm{OH}}$.

The vibrational distribution of the $\mathrm{OH}$ products from tpHOONO $\left(3 \nu_{\mathrm{OH}}\right)$ provides a more stringent test of the three statistical models. However, the $\mathrm{OH}(\nu=1)$ products are such a minor channel that we were unable to quantitatively determine the branching ratio summed over all the $\mathrm{OH}$ product rotational and fine-structure states. Instead, we measured a specific quantum state ratio for $\mathrm{OH} X^{2} \Pi_{3 / 2}, \quad\left(\nu=1, J_{\mathrm{OH}}\right.$ $=5 / 2) /\left(\nu=0, J_{\mathrm{OH}}=9 / 2\right)$, and compared this result with the analogous ratios from the three statistical models in Fig. 5 (gray bars). The SSE model prediction matches the experimental observation $(\sim 0.037)$ most closely with a ratio of 0.028. Both the PST and prior models predict even smaller quantum state ratios.

\section{DISCUSSION}

The second $\mathrm{OH}$ overtone transition of tp-HOONO has been definitively identified at $10195.32(5) \mathrm{cm}^{-1}$ (origin) through its vibrational frequency and rotational band structure under jet-cooled conditions $(5 \mathrm{~K})$. The observed transition frequency is in excellent accord with theoretical predictions. Varner and Stanton predicted a transition frequency of $10191 \mathrm{~cm}^{-1}$ using the $\operatorname{CCSD}(\mathrm{T})$ level of ab initio theory with the atomic natural orbital (ANO) basis set ${ }^{50}$ in conjunction with second-order vibrational perturbation theory. ${ }^{11,51}$ In addition, Matthews et al. predicted the same value in their scaled $a b$ initio transition frequency calculations. ${ }^{20}$ The prominent feature at $10160 \mathrm{~cm}^{-1}$ in the room-temperature spectrum reported by these same authors, however, cannot be attributed to tp-HOONO $\left(3 \nu_{\mathrm{OH}}\right)$, as previously suggested. ${ }^{20}$ Spectral simulations based on the parameters derived in this work show that the band position at $300 \mathrm{~K}$ will not shift appreciably from the reported band origin. The prominent feature in the second $\mathrm{OH}$ overtone spectrum at $300 \mathrm{~K}$ (Ref. 20 ) is most likely due to hot bands originating from excited torsional states of cc-HOONO, as recently reported for the first and second $\mathrm{OH}$ overtone transitions. ${ }^{12,15,16}$

Konen et al. have also computed the magnitude and direction of the transition dipole moment for the $\mathrm{OH}$ overtone transitions of tp-HOONO. ${ }^{11}$ Several different types of calculations were performed, which were based on second-order vibrational perturbation theory (VPT2) in full dimensionality [nine dimensional (9D)] and reduced dimensionality [one dimensional (1D)], and an exact 1D calculation. ${ }^{11}$ For the second overtone transition of tp-HOONO, the full dimensionality VPT2 calculation yields a ratio of $3.48: 1$ for the $a$ - to $c$-type transition intensities, which is in good accord with the experimental ratio of 4.2(7):1 determined in this work. The reduced dimensionality VPT2 calculation gives a similar ra- tio of 3.44:1, while the exact 1D calculation predicts a smaller $a: c$ ratio of 2.30:1. By comparison, the VPT2-9D calculation for the first overtone transition of tp-HOONO gives an $a: c$ ratio of 1.38:1, which is also in good agreement with the experimental ratio of 1.2(1):1. ${ }^{11}$ Reduced dimensionality calculations yield similar $a: c$ ratios of 1.36 (VPT2) and 1.22 (exact 1D). Both experiment and theory show that the direction of the transition dipole moment, as evidenced by the $a: c$ ratio, changes with increasing $\mathrm{OH}$ stretch excitation. The transition dipole shifts from approximately $35^{\circ}$ to $49^{\circ}$ with respect to the $\mathrm{OH}$ bond axis (in the $a-c$ plane) from the first to second $\mathrm{OH}$ overtone transition. This reflects changes in the charge distribution of the tp-HOONO molecule upon $\mathrm{OH}$ stretch excitation. ${ }^{38}$

Konen et al. ${ }^{11}$ and Varner and Stanton ${ }^{51}$ predicted the oscillator strength for the first $\mathrm{OH}$ overtone transition of tpHOONO to be $1.04 \times 10^{-6}$ and that for the second overtone transition to be $4.82 \times 10^{-8}$, indicating that the latter is $\sim 21$ times weaker. Matthews et al. predicted a similar 24-fold decrease in the integrated absorption cross section for the second $\mathrm{OH}$ overtone of tp-HOONO as compared with the first overtone at their highest level of theory. ${ }^{20}$ Experimentally, we estimate that the second overtone is about 14 times weaker than the first overtone of tp-HOONO.

The Lorentzian linewidth of $\Gamma=0.44(12) \mathrm{cm}^{-1}$ observed for the second $\mathrm{OH}$ overtone transition is about a factor of two times larger than that for the first overtone transition, $\Gamma=0.195(4) \mathrm{cm}^{-1} .{ }^{11}$ The corresponding lifetime of $12 \mathrm{ps}$ for tp-HOONO $\left(3 \nu_{\mathrm{OH}}\right)$ is attributed to IVR by analogy with the arguments used to explain the $2 \nu_{\mathrm{OH}}$ lifetime of $27(1) \mathrm{ps}{ }^{11}$ The factor of two change in lifetime and/or linewidth, however, is much smaller than might be predicted using Fermi's golden rule based on the change in the density of states (and an assumed constant average coupling strength). An anharmonic frequency state count yields a density of states increasing 7.5 -fold from 120 states per $\mathrm{cm}^{-1}$ at $2 \nu_{\mathrm{OH}}$ to 900 states per $\mathrm{cm}^{-1}$ at $3 \nu_{\mathrm{OH}}{ }^{52-54}$ This suggests that the optically bright $\mathrm{OH}$ stretch is coupled strongly to only a small subset of vibrational states (first tier), and that most of the states in the count are more weakly coupled background states. Thus, the experimental linewidth measurements are consistent with a tier model for IVR. ${ }^{55-57}$

The statistical $\mathrm{OH}$ product state distributions observed following $2 \nu_{\mathrm{OH}}$ and $3 \nu_{\mathrm{OH}}$ excitation of tp-HOONO indicate some degree of energy randomization prior to dissociation, which occurs faster than the temporal resolution of our lasers (6-8 ns). The tp-HOONO dissociation rates are much slower than predicted by the Rice-Ramsperger-KasselMarcus theory $(\leqslant 1 \mathrm{ps}),{ }^{11}$ presumably because the coupling of the high-frequency $\mathrm{OH}$ stretch to other states is a ratelimiting step in the dissociation process. In addition, the observed statistical distributions provide no evidence of a barrier $\left(\sim 4.5 \mathrm{kcal} \mathrm{mol}^{-1}\right)$ to dissociation of tp-HOONO, which is evident in theoretical calculations. ${ }^{58,59}$ This suggests that dissociation of tp-HOONO $\left(2 \nu_{\mathrm{OH}}\right.$ and $\left.3 \nu_{\mathrm{OH}}\right)$ may involve isomerization to the cc-HOONO conformer followed by barrierless dissociation. ${ }^{58}$ The initial $\mathrm{OH}$ overtone excitation prepares tp-HOONO far above the conformational barrier separating tp- from cc-HOONO. ${ }^{13}$ 
Finally, we have not yet seen any spectroscopic evidence for cc-HOONO in jet-cooled spectra in the first or second $\mathrm{OH}$ overtone region, despite significant effort in spectroscopic searches. We have previously rationalized our inability to observe the first $\mathrm{OH}$ overtone transition of ccHOONO, reported at $6365 \mathrm{~cm}^{-1}$ under thermal conditions, as resulting from the increased binding energy of the ccHOONO conformer $\left(19.6 \mathrm{kcal} \mathrm{mol}^{-1}\right) .{ }^{11}$ This binding energy would imply that only spectral features with transition frequencies greater than $6860 \mathrm{~cm}^{-1}$ should be observable by infrared action spectroscopy under jet-cooled conditions.

On the other hand, the second overtone transition will supply more than sufficient energy for the dissociation of cc-HOONO. Thus, our inability to observe cc-HOONO $\left(3 \nu_{\mathrm{OH}}\right)$ under jet-cooled conditions likely arises from (1) inadequate transition strength or other related factors that make cc-HOONO more difficult to observe spectroscopically or (2) insufficient production of the more stable cc-HOONO conformer in our photolytic source. The latter can be overcome by switching to an alternate synthetic route for the production of cc-HOONO from $\mathrm{H}_{2} \mathrm{O}_{2}+\mathrm{BF}_{4} \mathrm{NO},{ }^{12,13,21}$ which is in progress. The former could arise from the twofold weaker transition strength computed for the second $\mathrm{OH}$ overtone of cc-HOONO compared with tp-HOONO ${ }^{20,51}$ or perhaps additional line broadening (reducing the peak amplitude) due to faster IVR for this conformer. ${ }^{13}$ We estimate that a spectroscopic feature three to five times smaller than tpHOONO $\left(3 \nu_{\mathrm{OH}}\right)$ would be indistinguishable from baseline noise at the scan speeds required to span the search region in a reasonable time. To date, spectroscopic searches have been conducted from 8865 to $9563 \mathrm{~cm}^{-1}$ to look for cc-HOONO $\left(3 \nu_{\mathrm{OH}}\right)$, with the broad scan range being dictated by an earlier study under thermal conditions. ${ }^{20}$

\section{CONCLUSIONS}

The second $\mathrm{OH}$ overtone transition of tp-HOONO has been identified under jet-cooled conditions based on its vibrational frequency $\left(10195.3 \mathrm{~cm}^{-1}\right)$ and rotational band structure. When combined with analogous measurements for the first overtone transition of tp-HOONO, ${ }^{11,22}$ the $\mathrm{OH}$ local mode can be characterized by a harmonic frequency of $\omega_{e}$ $=3747.5 \mathrm{~cm}^{-1}$ and an anharmonicity of $\omega_{e} x_{e}=87.3 \mathrm{~cm}^{-1}$. While the band contour for the second overtone could be simulated using rotational constants derived from the first overtone spectrum, ${ }^{11}$ the $a: c$ ratio of the transition-type is shown to change with increasing $\mathrm{OH}$ stretch excitation. This is indicative of charge redistribution within tp-HOONO (Ref. 38) that results in the transition dipole moment shifting from $35^{\circ}$ to $49^{\circ}$ with respect to the $\mathrm{OH}$ bond axis from the first to second $\mathrm{OH}$ overtone transition. The spectral linewidths demonstrate that the initial stage of IVR occurs about a factor of two faster for $3 \nu_{\mathrm{OH}}$ as compared with $2 \nu_{\mathrm{OH}}$ excitation of tp-HOONO. The second overtone is shown to be more than an order of magnitude $(\sim 14$-fold $)$ weaker than the first $\mathrm{OH}$ overtone transition of tp-HOONO.

The nascent quantum state distribution of the $\mathrm{OH}(\nu$ $=1)$ and $(\nu=0)$ products from unimolecular dissociation of tp-HOONO $\left(3 \nu_{\mathrm{OH}}\right)$ has been measured and, along with that previously observed for tp-HOONO $\left(2 \nu_{\mathrm{OH}}\right),{ }^{11}$ compared with the results of three different statistical models, namely, a prior distribution (prior), phase-space theory (PST), and the separate statistical ensembles (SSE) model. All of the experimental results are consistent with a previously determined binding energy for tp-HOONO of $D_{0}=5667(38) \mathrm{cm}^{-1}$ or $16.2(1) \mathrm{kcal} \mathrm{mol}^{-1} .{ }^{11}$ The $\mathrm{OH}$ $(\nu=0)$ rotational distributions from tp-HOONO $\left(2 \nu_{\mathrm{OH}}\right.$ or $\left.3 \nu_{\mathrm{OH}}\right)$ peak at low $J_{\mathrm{OH}}$ and extend to the energetic limits dictated by the excitation frequency and binding energy. By comparing with the $\mathrm{OH}(\nu=0)$ product state distributions predicted from the three different statistical models, the experimental distributions are shown to be statistical, with no lambda-doublet or spin-orbit propensities. The $\mathrm{OH}(\nu=0)$ distributions show no evidence of an angular momentum constraint or any type of barrier moderating the dissociation dynamics of tp-HOONO $\left(2 \nu_{\mathrm{OH}}\right.$ or $\left.3 \nu_{\mathrm{OH}}\right)$.

Vibrationally excited $\mathrm{OH}(\nu=1)$ is shown to be a very small fraction of the products from tp-HOONO $\left(3 \nu_{\mathrm{OH}}\right)$, both experimentally and as predicted from the statistical theories. Nevertheless, the relative amount of $\mathrm{OH}(\nu=1)$ vs $(\nu=0)$ fragments can be used to distinguish between the various statistical models. The SSE model provides the best representation of the $\mathrm{OH} X^{2} \Pi_{3 / 2}(\nu=1) /(\nu=0)$ population ratio observed in specific reference channels, as expected based on its formulation, and indicates that less than $2 \%$ of the $\mathrm{OH}$ fragments will be vibrationally excited. In addition, the statistical calculations predict that the higher energy $\mathrm{HO}_{2}+\mathrm{NO}$ channel (as yet unobserved) will make a significant contribution $(21.5 \%)$ to the total product yield from tp-HOONO $\left(3 \nu_{\mathrm{OH}}\right)$.

\section{ACKNOWLEDGMENTS}

This research was sponsored by the Chemistry Division of the National Science Foundation. One of the authors (T.A.S.) is a recipient of a Eugene M. Lang Faculty Fellowship from Swarthmore College in support of his 2004-2005 academic year sabbatical leave. The authors thank Mychel E. Varner and John F. Stanton (University of Texas at Austin) for sharing the results of their $3 \nu_{\mathrm{OH}}$ calculations for HOONO prior to publication. We also acknowledge helpful discussions with group members Ilana B. Pollack and Craig R. Murray.

${ }^{1}$ B. J. Finlayson-Pitts and J. N. Pitts, Chemistry of the Upper and Lower Atmosphere: Theory, Experiments, and Applications (Academic, San Diego, 2000).

${ }^{2}$ D. M. Golden and G. P. Smith, J. Phys. Chem. A 104, 3991 (2000).

${ }^{3}$ N. M. Donahue, R. Mohrschladt, T. J. Dransfield, J. G. Anderson, and M. K. Dubey, J. Phys. Chem. A 105, 1515 (2001).

${ }^{4}$ H. Hippler, S. Nasterlack, and F. Striebel, Phys. Chem. Chem. Phys. 4, 2959 (2002).

${ }^{5}$ D. M. Golden, J. R. Barker, and L. L. Lohr, J. Phys. Chem. A 107, 11057 (2003).

${ }^{6}$ J. S. Robertshaw and I. W. M. Smith, J. Phys. Chem. 86, 785 (1982).

${ }^{7}$ J. B. Burkholder, P. D. Hammer, and C. J. Howard, J. Phys. Chem. 91, 2136 (1987)

${ }^{8}$ M. P. McGrath and F. S. Rowland, J. Phys. Chem. 98, 1061 (1994).

${ }^{9}$ D. A. Dixon, D. Feller, C.-G. Zhan, and J. S. Francisco, J. Phys. Chem. A 106, 3191 (2002).

${ }^{10}$ B. D. Bean, A. K. Mollner, S. A. Nizkorodov, G. Nair, M. Okumura, S. P. Sander, K. A. Peterson, and J. S. Francisco, J. Phys. Chem. A 107, 
6974 (2003).

${ }^{11}$ I. M. Konen, I. B. Pollack, E. X. J. Li, M. I. Lester, M. E. Varner, and J. F. Stanton, J. Chem. Phys. 122, 094320 (2005).

${ }^{12}$ I. Matthews and A. Sinha, J. Chem. Phys. 122, 104313 (2005).

${ }^{13}$ J. Fry, S. A. Nizkorodov, M. Okumura, C. M. Roehl, J. S. Francisco, and P. O. Wennberg, J. Chem. Phys. 121, 1432 (2004).

${ }^{14}$ M. P. McGrath and F. S. Rowland, J. Chem. Phys. 122, 134312/1 (2005).

${ }^{15}$ D. P. Schofield and H. G. Kjaergaard, J. Phys. Chem. A 109, 1810 (2005).

${ }^{16}$ A. B. McCoy, J. L. Fry, J. S. Francisco, A. K. Mollner, and M. Okumura, J. Chem. Phys. 122, 104311 (2005).

${ }^{17}$ B. M. Cheng, J. W. Lee, and Y. P. Lee, J. Phys. Chem. 95, 2814 (1991).

${ }^{18}$ W.-J. Lo and Y. P. Lee, J. Chem. Phys. 101, 5494 (1994).

${ }^{19}$ S. A. Nizkorodov and P. O. Wennberg, J. Phys. Chem. A 106, 855 (2002).

${ }^{20}$ J. Matthews, A. Sinha, and J. S. Francisco, J. Chem. Phys. 120, 10543 (2004)

${ }^{21}$ B. J. Drouin, J. L. Fry, and C. E. Miller, J. Chem. Phys. 120, 5501 (2004)

${ }^{22}$ I. B. Pollack, I. M. Konen, E. X. J. Li, and M. I. Lester, J. Chem. Phys. 119, 9981 (2003)

${ }^{23}$ L. S. Rothman, C. P. Rinsland, A. Goldman et al., J. Quant. Spectrosc. Radiat. Transf. 60, 665 (1998).

${ }^{24}$ G. H. Dieke and H. M. Crosswhite, J. Quant. Spectrosc. Radiat. Transf. 2, 97 (1962).

${ }^{25}$ J. Luque and D. R. Crosley, LIFBASE: dabatase and spectral simulation, Version 1.5, SRI International Report No. MP 99, 1999.

${ }^{26}$ D. R. Yarkony, J. Chem. Phys. 97, 1838 (1992).

${ }^{27}$ G. Parlant and D. R. Yarkony, J. Chem. Phys. 110, 363 (1999).

${ }^{28}$ J. M. Hossenlopp, D. T. Anderson, M. W. Todd, and M. I. Lester, J. Chem. Phys. 109, 10707 (1998).

${ }^{29}$ I. M. Konen and M. I. Lester (unpublished).

${ }^{30}$ G. Herzberg, Molecular Spectra and Molecular Structure: Spectra of Diatomic Molecules (Van Nostrand, New York, 1950).

${ }^{31}$ K. J. Feierabend, D. K. Havey, and V. Vaida, Spectrochim. Acta, Part A 60A, 2775 (2004).

${ }^{32}$ P. R. Fleming, M. Li, and T. R. Rizzo, J. Chem. Phys. 94, 2425 (1991)

${ }^{33}$ D. J. Donaldson, J. J. Orlando, S. Amann, G. S. Tyndall, R. J. Proos, B. R. Henry, and V. Vaida, J. Phys. Chem. A 102, 5171 (1998).

${ }^{34}$ A. Sinha, R. L. Vander Wal, and F. F. Crim, J. Chem. Phys. 92, 401 (1990).

${ }^{35}$ A. Sinha, R. L. Vander Wal, and F. F. Crim, J. Chem. Phys. 91, 2929 (1989), and references cited therein.
${ }^{36}$ J. A. Coxon, Can. J. Phys. 58, 933 (1980).

${ }^{37}$ K. Takahashi, M. Sugawara, and S. Yabushita, J. Phys. Chem. A 109, 4242 (2005)

${ }^{38}$ T. A. Stephenson, I. M. Konen, and M. I. Lester (unpublished).

${ }^{39}$ Using phase-space theory (PST), the fraction of $\mathrm{OH}$ products in the specified product state, $\nu=0, J_{\mathrm{OH}}=9 / 2, \Omega=3 / 2, \Pi\left(A^{\prime \prime}\right)$, was 0.061 for tpHOONO $\left(3 \nu_{\mathrm{OH}}\right)$ and 0.117 for $\left(2 \nu_{\mathrm{OH}}\right)$. The separate statistical ensembles (SSE) model yields similar fractional populations. See Sec. IV for a description of the statistical models.

${ }^{40}$ Using PST to estimate the branching fraction for the $\mathrm{HO}_{2}+\mathrm{NO}$ product channel (see Sec. IV) reduces the oscillator strength ratio to $\sim 11$.

${ }^{41}$ R. G. Gilbert and S. C. Smith, Theory of Unimolecular and Recombination Reactions (Blackwell Scientific, Oxford, 1990).

${ }^{42}$ T. Baer and W. L. Hase, Unimolecular Reaction Dynamics (Oxford University Press, New York, 1996)

${ }^{43}$ M. Hunter, S. A. Reid, D. C. Robie, and H. Reisler, J. Chem. Phys. 99, 1093 (1993)

${ }^{44}$ C. Wittig, I. Nadler, H. Reisler, M. Noble, J. Catanzarite, and G. Radhakrishnan, J. Chem. Phys. 83, 5581 (1985).

${ }^{45}$ H. D. Bist and J. C. D. Brand, J. Mol. Spectrosc. 62, 60 (1976).

${ }^{46}$ J. Zhang, T. Dransfield, and N. M. Donahue, J. Phys. Chem. A 108, 9082 (2004).

${ }^{47}$ J. D. DeSain, A. D. Ho, and C. A. Taatjes, J. Mol. Spectrosc. 219, 163 (2003).

${ }^{48}$ J. B. Burkholder, P. D. Hammer, C. J. Howard, J. P. Towle, and J. M. Brown, J. Mol. Spectrosc. 151, 493 (1992).

49 J. M. Brown, A. R. H. Cole, and F. R. Honey, Mol. Phys. 23, 287 (1972).

${ }^{50}$ J. Almlöf and P. R. Taylor, J. Chem. Phys. 86, 4070 (1987).

${ }^{51}$ M. E. Varner and J. F. Stanton (private communication).

${ }^{52}$ The state count neglected Coriolis coupling and treated the HOON torsion as a hindered rotor in a sinusoidal well with a well-defined fundamental frequency and reduced moment of inertia. The anharmonic frequency state count was performed using the MULTIWELL program suite.

${ }^{53}$ J. R. Barker, N. F. Ortiz, J. M. Preses, and L. L. Lohr, MULTIwELL-1.4.1 software, http://aoss.engin.umich.edu/multiwell/ (2004).

${ }^{54}$ J. R. Barker, Int. J. Chem. Kinet. 33, 232 (2001).

${ }^{55}$ P. R. Stannard and W. M. Gelbart, J. Phys. Chem. 85, 3592 (1981).

${ }^{56}$ K. K. Lehmann, G. Scoles, and B. H. Pate, Annu. Rev. Phys. Chem. 45, 241 (1994).

${ }^{57}$ D. J. Nesbitt and R. W. Field, J. Phys. Chem. 100, 12735 (1996).

${ }^{58}$ K. Doclo and U. Rothlisberger, Chem. Phys. Lett. 297, 205 (1998).

${ }^{59}$ Y. Zhao, K. N. Houk, and L. P. Olson, J. Phys. Chem. A 108, 5864 (2004). 